\title{
TURISMO EM FAVELAS NO RIO DE JANEIRO EM TEMPOS DE CRISE: ainda uma atividade possível?
}

\section{TOURISM IN RIO DE JANEIRO'S SLUMS IN THE SCENARIO OF CRISIS: still a feasible activity?}

\author{
A. Sergio Moraes Rego Fagerlande \\ Prourb FAU, Universidade Federal do Rio de Janeiro, Brasil \\ sfagerlande@gmail.com
}

\section{RESUMO}

A realização dos eventos esportivos como a Copa do Mundo de 2014 e os Jogos Olímpicos de 2016 propiciaram grandes investimentos em obras na cidade, também em diversas favelas. A implantação de política de segurança com as Unidades de Política Pacificadora (UPPs) e grandes obras de mobilidade urbana foram fundamentais para o desenvolvimento do turismo nessas áreas. Ao lado de iniciativas que estimularam o turismo de base comunitária algumas favelas da Zona Sul carioca se tornaram palco dessas atividades, com visitação e hospedagem. Exemplos nas favelas Santa Marta e Cantagalo-Pavão-Pavãozinho mostram a importância da atuação governamental para o turismo em favelas. Dessa maneira o fim das UPPs e o fechamento ou mau funcionamento dos equipamentos de mobilidade urbana trazem dúvidas sobre a viabilidade do turismo em favelas.

Palavras-chave: turismo em favelas, grandes eventos esportivos, políticas públicas, turismo de base comunitária

Linha de Investigação: 3: Dinâmicas Urbanas

Tópico: Turismo

\section{ABSTRACT}

\begin{abstract}
The hosting of sports events such as the 2014 World Football Cup and the 2016 Olympic Games produced a sizeable flow of investments in the city, including some favelas. The implementing of a security policy that implemented the UPPs - Peace Police Corps - and major work aimed at improving urban mobility were fundamental actions to foster the development of tourism in these areas. As a result of the initiatives that sought to stimulate community-based tourism, some slums in Rio's South End became the stage for a number of activities that included visitation and accommodation offerings. Examples on the Santa Marta and Cantagalo-Pavão-Pavãozinho communities show the importance of public actions to stimulate tourism in the favelas. As a result, as the UPPs were closed and many of the urban mobility equipment shut down, many doubts were cast on the feasibility and continuity of tourism activities in Rio's favelas.
\end{abstract}

Keywords: Tourism in slums; major sport events; public policies, community-based tourism

Research line: 3: Urban Dynamics

Topic: Tourism 


\section{SÃO PAULO15 $\sim 17 \cdot$ LISBOA $25 \sim 26$ JUN 2020

\section{Introdução}

O turismo em favelas cariocas teve um momento de grande desenvolvimento entre os anos de 2010 e 2016, em parte devido a um conjunto de iniciativas governamentais relativas aos eventos esportivos que a cidade iria receber, como a Copa do Mundo de 2014 e os Jogos Olímpicos de 2016. Desde o anúncio em 2007 que o Brasil sediaria a Copa do Mundo, e em 2009 o anúncio de que o Rio de Janeiro sediaria os Jogos Olímpicos, os diversos níveis de governo anunciaram iniciativas ligadas a questões urbanas visando a realização dos eventos. Ao lado das necessárias obras de instalações esportivas viriam as obras de infraestrutura de mobilidade urbana e uma política de segurança pública, com as Unidades de Polícia Pacificadora, UPP. Essas unidades em geral se localizaram em favelas situadas em áreas relacionadas aos eventos, e em algumas dessas comunidades também passaram a ser implantadas obras de infraestrutura e mobilidade urbana. Dentro desse contexto o turismo em favelas passou a ser estimulado como uma possibilidade de integração dessas áreas à cidade dita formal. Da mesma forma que o turismo foi uma estratégia utilizada em áreas da cidade, como na área portuária com o projeto Porto Maravilha, o turismo em favelas também seria utilizado para a construção de uma nova imagem da cidade, segura e menos desigual.

Esse artigo busca mostrar como esse processo de turismo em favelas no período estudado foi estimulado através de políticas públicas como o edital de chamada pública MTur/n.001/2008, que incentivava o turismo de base comunitária, inclusive as favelas cariocas (Silva, Ramiro \& Teixeira, 2009). Tratava-se uma poolítica visando aumentar as condições de renda em áreas como quilombos, comunidades tradicionais, indígenas e favelas. Através de financiamento público associações locais poderiam oferecer melhores condições para receber visitantes. Além disso outro projeto relacionado ao turismo comuinitário foi o Projeto Rio Top Tour, iniciado na favela Santa Marta, lançado em 2010. A importância da políticas públicas para o processo do turismo em favelas fica claro ao se entender como a como a falência do estado do Rio de Janeiro e o fim das UPP em 2018 teve forte impacto sobre o turismo em favelas, mas não determinou necessariamente seu fim, mas a necessidade de se ter cada vez mais a participação comunitária para o êxito do modelo pensado.

A partir de pesquisa que vem sendo realizada em favelas turísticas da Zona Sul carioca, está sendo apresentado nesse trabalho estudo mais específico focado nas favelas de Santa Marta e de CantagaloPavão-Pavãozinho, locais impactadas tanto pela atuação das UPP como por obras de mobilidade urbana, com um plano inclinado e um elevador-mirante, além de praças, mirantes e vias internas.

São favelas que também experimentaram projetos comunitários financiados pelo edital do Ministério do Turismo de TBC de 2008. Essas favelas têm ações de turismo comunitário, no caso da Santa Marta ainda originado pelo Rio Top Tour e no Cantagalo-Pavão-Pavãozinho uma ONG financiada por ações públicas, o Museu de Favela, MUF, ainda mantém forte movimentação de guiamentos pela favela, mesmo em tempos de crise da segurança pós UPP. A pesquisa vem sido realizada com metodologia quantitativa e qualitativa, com contatos diretos com moradores e organizações de moradores ligadas ao turismo, além de ter mapeado iniciativas de turismo como albergues (hostels), bares e restaurantes nas comunidades estudadas. Mesmo com todas as dificuldades para se realizar pesquisa em favelas, locais por essência informais, a pesquisa traz resultados em termos de localização e identificação dos albergues instalados entre 2010 e 2018 . Os resultados mostram um crescimento intenso até 2016, e o quase total fechamento dessas iniciativas após essa data.

A localização dos empreendimentos mostra sua direta relação com os investimentos em mobilidade urbana nos casos estudados, por suas proximidades tanto com o Plano Inclinado, no caso de Santa Marta, como do 


\section{SÃO PAULO15 17 LISBOA $25 \sim 26$ JUN 2020

Elevador-mirante e de vias internas do projeto patrocinado pelo PAC Comunidades ${ }^{1}$, no caso do CantagaloPavão-Pavãozinho. Por outro lado a visitação ainda se mantém, mostrando que essas iniciativas, desde que com direta participação dos agentes locais, seja como organizações comunitárias como o MUF seja com agentes ligados à comunidade, como os guias turísticos locais da favela Santa Marta, ainda trazem alento ao turismo em favelas como uma possibilidade de geração de renda, integração entre essas áreas segregadas e os demais bairros da cidade, processo que ao se iniciar com as iniciativas ligadas às tentativas de maior empoderamento de comunidades como foi o TBC.

$O$ estudo do turismo em favelas não pode ser pensado de maneira diferente, em alguns aspectos, de características gerais do turismo como nos mostra Urry (2001). A ideia de afastamento, busca do exótico e de entendermos o turista como diverso, e não um único tipo, ajuda a entender o turismo em favelas. FreireMedeiros (2009), Fagerlande $(2016,2017)$, tem estudado o turismo em favelas no Rio de Janeiro. A atuação das populações locais no turismo forma a base do chamado Turismo de Base Comunitária, como aparece no livro publicado pelo Ministério do Turismo em 2009, de Bartholo, Sansolo \& Bursztyn. Rodrigues (2014) e Carvalho (2016) tratam o turismo comunitário na favela Dona Marta permitindo entender a implantação de projetos governamentais relacionados a esse tema, como o Rio Top Tour. Contribuições fora do Brasil, tratam questões ligadas ao turismo de pobreza, sua história desde o século XIX na Europa e nos Estados Unidos e seu desenvolvimento em diversas periferias do mundo (Frenzel, Koens \& Steinbrink, 2012). A ideia de que o turismo pode gerar renda para áreas pobres convive com problemas como a chamada expulsão branca e gentrificação (Perlman, 2016).

Mesmo com a grave crise e as poucas possibilidades que se vêm no horizonte do país, será que ainda é possível pensar que a atuação de moradores pode diminuir a invisibilidade dessas comunidades através do turismo, mesmo que agora sem nenhum apoio de governos. Se por um lado os empreendimentos realizados de maneira mais comercial nessas favelas, caso de parte dos hostels, foram os primeiros a fechar, os de empreendedores locais ainda persistem, mesmo com dificuldades, e a visitação por parte dos agente locais também mostram como as políticas públicas quando se conectam com as comunidades podem deixar raízes difíceis de serem arrancadas.

\section{Origens do turismo em favelas: valorização do diferente e da observação das situações de pobreza}

Urry (2001) fala que o turismo se caracteriza como uma atividade "moderna", estabelecendo uma relação entre a produção, consumo e a sociedade. A partir do conceito de afastamento Urry trata de como o turista busca uma ruptura de sua vida diária, e busca muitas vezes vivenciar experiências distantes de sua realidade. Podemos considerar esse um dos aspectos do chamado turismo de pobreza, e do turismo em favelas. A literatura sobre o turismo trata em geral desse aspecto, de como a ideia de viajara para conhecer outros lugares está, de maneira geral, ligada a essas questões. Por certo não existe somente um único tipo de turista, e por isso a necessidade de criação de novos destinos para a visitação é outro aspecto a ser considerado ao se pensar no turismo em favelas.

Turismo é de maneira geral movimentação pelo espaço, e os lugares podem ser escolhidos para serem contemplados nessa perspectiva. Urry (2001) fala da importância de uma variedade de práticas para a construção dessas práticas, como cinema, televisão, literatura, revistas e outras mídias que reforçam o olhar. Nesse sentido Freire-Medeiros (2009) fala de como a filmagem de clipe de Michael Jackson em 1996 na

1 PAC Comunidades foi um Programa de Aceleração do Crescimento, programa do governo federal para financiamento de obras públicas em comunidades. 


\section{SÃO PAULO15 $\sim 17 \cdot$ LISBOA $25 \sim 26$ JUN 2020

favela Santa Marta, e filmes como "Cidade de Deus", de 2002 e novelas filmadas em favelas, como "Caminho das Índias" da TV Globo, de 2007, tornaram mais atrativos esses lugares de pobreza e de exotismo.

Esse interesse pela visitação de áreas de pobreza, no entanto, não surgiu recentemente. Durante o século XIX, o "slumming" (visitação de áreas de slum) já podia ser verificado na Inglaterra a partir de 1840 (Frenzel, Koens \& Steinbrink, 2012) e nos Estados Unidos a partir dos anos 1880. A partir do século XX o processo de turismo em áreas de pobreza passou a ser verificado não mais somente no norte global, mas também em áreas do sul global. Podem ser verificadas atividades de turismo em favelas na África do Sul nos anos 1970, ainda durante o regime do apartheid, realizado por Organizações Não Governamentais, buscando geração de renda para essas populações. Posteriormente, considera-se que a prática ressurge simultaneamente na África do Sul pós apartheid e no Rio de Janeiro nos anos 1990 (Freire-Medeiros, 2009; Frenzel, Koens \& Steinbrink, 2012), durante a realização da ECO 92 (United Nations Conference on Environment and Development) no Rio de Janeiro, o interesse de grupos de participantes e acadêmicos levou a serem realizados passeios guiados em favelas como a Rocinha, por empresas comerciais, o que passou a ser um estímulo ao estabelecimento de roteiros com guias e empreendedores locais (Freire-Medeiros, 2009).

Durante os anos 1990 as favelas cariocas passavam por momento de grandes transformações, em parte devido a iniciativas como o projeto Favela-Bairro, que a partir de 1993 passou a realizar intervenções urbanísticas em diversas favelas do Rio de Janeiro. Esse novo olhar sobre as favelas e a necessidade de urbanização de suas áreas públicas pode ser relacionado com esse novo processo de turismo em favelas cariocas, pioneiro no Brasil, assim como foi o Projeto Favela Bairro. A ideia de melhor conhecer as favelas através de visitação turística, e não somente por pequenos grupos de acadêmicos e pesquisadores passou a tornar mais visível essas áreas da cidade. A possibilidade de geração de renda também foi um dos aspectos considerados (Steinbrink, Frenzel \& Koens, 2012)

A ideia do passeio na favela como algo exótico e selvagem se relaciona com o que muitos consideram como uma exposição dos moradores de favela em uma espécie de "zoológico de pobres", (Freire-Medeiros, 2009, p.28), onde os moradores (e suas realidades) terminam por ser reduzidos a meras atrações para a curiosidade e deleite do expectador. Trata-se ampla discussão, mesmo entre as comunidades. Uma das alternativas para o turismo em favelas tem sido o Turismo de Base Comunitária (TBC). A ideia da participação dos próprios moradores teve um momento de expansão a partir de iniciativas do Ministério do Turismo, que em 2008 implantou um projeto destinado ao financiamento de iniciativas em todo o país, muitas em favelas (Silva, Ramiro \& Teixeira, 2009).

Se por um lado o turismo em favelas traz a possibilidade de uma maior exposição e integração com as outras áreas da cidade, em especial novas relações com suas bordas, a valorização imobiliária trouxe questões como a gentrificação e a chamada expulsão branca (Perlman, 2016), processos muitas vezes relacionados com o turismo e com as intervenções urbanísticas em áreas antes excluídas da cidade.

\section{Turismo nas favelas do Rio de Janeiro: caso do Cantagalo-Pavão-Pavãozinho e Santa Marta}

O turismo em favelas no Rio de Janeiro se concentrou nas comunidades localizadas em áreas em que além de potencial cultural a paisagem foi outro fator de estímulo para que sejam locais atraentes para a visitação. Se as agências de turismo ou guias individuais sempre foram parte do processo de visitação, em especial em favelas como a Rocinha e Vidigal, por exemplo, cada vez mais o turismo de favelas no Rio de Janeiro vem 


\section{SÃO PAULO15 $\sim 17 \cdot$ LISBOA $25 \sim 26$ JUN 2020

sendo realizado a partir da base comunitária, ou seja, são os próprios moradores (por meio de associações de moradores, cooperativas ou ONGs), com formação na área, que realizam as rotas e passeios nas favelas.

Nesse contexto, o turismo de base comunitária passa a ser não mais focado somente no turista em si, mas no próprio território, com o objetivo principal de produzir novas narrativas (por vezes contrahegemônicas) sobre as favelas e seus habitantes. Além disso, tais práticas surgem como uma nova fonte de renda para os moradores, algo que raramente ocorre quando grupos comerciais de maior porte estão à frente do processo. Se o turismo em favelas no Rio de Janeiro passou a ser desenvolvido desde 1992, somente após a criação de politicas públicas ligadas à mobilidade urbana e principalmente à melhoria das condições de segurança pública, com a criação das Unidades de Polícia Pacificadora (UPP's) em 2008, o turismo passou a ser uma atividade mais viável, tanto em termos de visitação como em termos de hospedagem. A presença e as disputas entre diferentes facções do tráfico e milícias apresentam-se como fatores que repelem visitantes externos, afetando diretamente a presença de visitantes e, consequentemente, o surgimento de empreendimentos voltados para esse novo público.

Desde sua implantação a política da UPP foi controversa e ambígua (Franco, 2014), com denúncias de abusos. Também existem relatos de que a UPP, ao controlar as atividades nos espaços públicos, passou a privilegiar eventos e empreendimentos voltados para o turismo, enquanto as atividades tradicionais e locais dos moradores passaram a ser proibidas ou menos estimuladas, podendo ser incluídos os bailes funk (Comelli, Anguelovski \& Chu, 2018). Por outro lado, dados estatísticos mostram uma redução significativa da violência nos territórios de favela onde há UPP, especialmente durante seus primeiros anos de existência (Burgos et al., 2011).

\subsection{Favela Santa Marta: inicio do projeto de UPP's e o turismo em favelas}

A primeira favela a receber uma UPP foi Santa Marta. Pequena favela localizada em Botafogo, na Zona Sul carioca, a partir de 2008 foi palco de diversas experiências ligadas a essas políticas públicas ligadas aos grandes eventos e à uma tentativa de mudança da imagem da cidade. Além da ocupação policial com a UPP, garantindo a segurança e a livre circulação de visitantes e de novos empreendedores na favela, foi palco da criação de um projeto piloto sobre turismo em favelas, o Rio Top Tour, a partir de 2010 (Rodrigues, 2014). Esse projeto foi parte de uma política do governo estadual para que atividades ligadas ao turismo fosse parte das mudanças esperadas para as favelas. Esse projeto se conecta com as políticas federais de turismo comunitário, dentro do chamado Turismo de Base Comunitário, que o Ministério do Turismo tinha lançado em 2008. A ideia de que as atividades ligadas ao turismo pudessem ser instrumentos de transformações sociais e urbanas é recorrente, e no Rio de Janeiro aparece no Projeto Porto Maravilha, com a construção de museus e bulevares para a fruição de visitantes e turistas (Wilheim, 2014; Barretto, 2014).

A urbanização teve a construção de um plano inclinado, inaugurado em 2008, como base para um projeto de construção de mirantes, vias internas e caminhos que passaram a ser utilizados para a visitação. O Rio Top Tour teve forte influência na formação de guias comunitários, e o surgimento de albergues junto às estações do plano inclinado mostra a importância desse equipamento de mobilidade para o turismo.

Mesmo sendo uma favela bastante visitada, a presença de albergues sempre foi pequena (Figura 01). Uma das razões para isso pode ser por estar localizada em Botafogo, um bairro pouco turístico. Na pesquisa realizada verificou-se que a maior incidência de albergues dava-se em favelas localizadas junto aos bairros turísticos próximos às praias, como Ipanema, Copacabana, Leblon e São Conrado, diminuindo em locais com menor rede de hospedagem, que é caso de Botafogo. 


\section{SÃO PAULO15 17 LISBOA $25 \sim 26$ JUN 2020}

Seminário Internacional de Investigação em Urbanismo

Seminario Internacional de Investigación en Urbanismo

O grande número de albergues mostra a possibilidade dessa atividade se relacionar tanto com a favela como com os bairros vizinhos. O levantamento mostra que nove albergues levantados se encontram em meio à favela, e doze em suas bordas, nesse caso na principal rua de acesso, a Rua Saint Romain. Esse fato ao mesmo tempo em que traz a possibilidade de se ter hospedagem não somente dentro da favela, mas próximo a ela, mostra um exemplo do que pode ser considerado em termos urbanísticos como uma "contaminação positiva", em que ao contrário do que ocorreu anteriormente, quando essa rua passava por um processo de desvalorização imobiliário, a ocupação com albergues e pequenos hotéis e pousadas traz um novo momento em que o turismo se relaciona com a melhoria do espaço urbano da favela e de seu entorno, no caso os bairros de Copacabana e Ipanema.

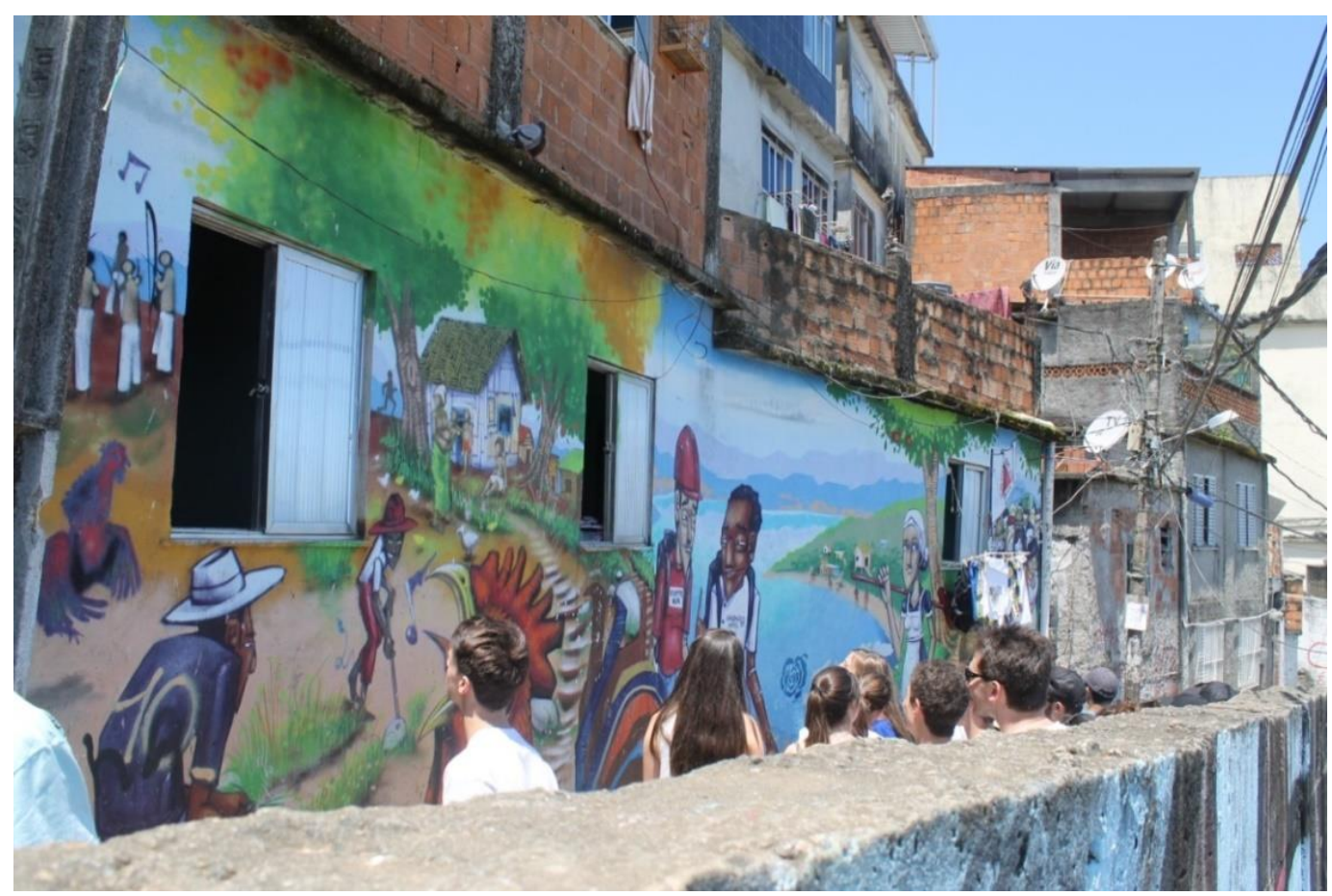

Figura 02: Visitação no Circuito Casas-Tela, do Museu de Favela, no Cantagalo-Pavão-Pavãozinho. Fonte: Foto do autor, 2014. 


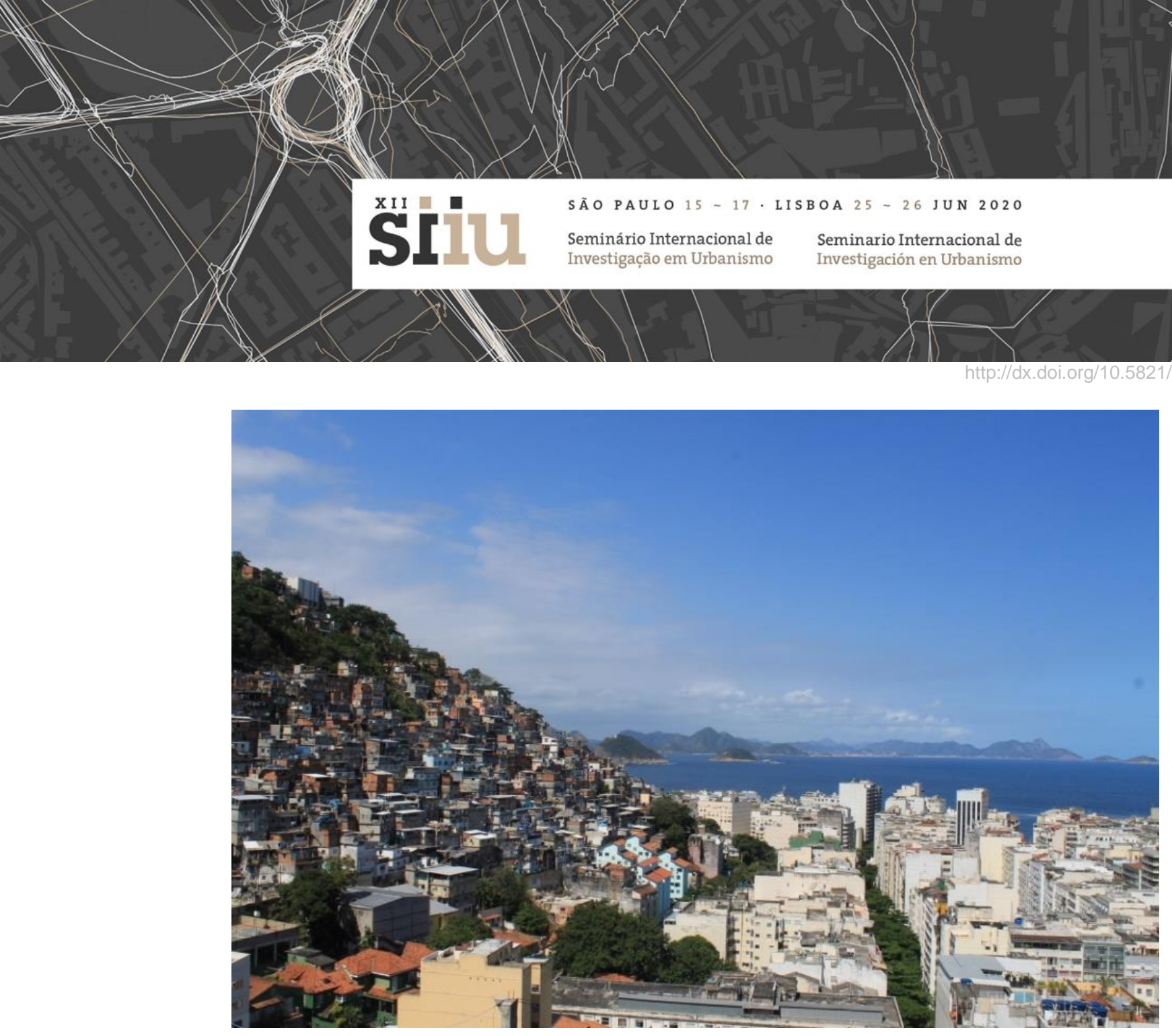

Figura 03: Vista da Favela do Cantagalo-Pavão-Pavãozinho. Fonte: Foto do autor, 2014

A figura 03 mostra uma imagem significativa da importância da situação geográfica de favelas como o Cantagalo-Pavão-Pavãozinho, que torna a paisagem um importante elemento para o turismo. E da mesma forma que na Santa Marta, a localização dos albergues mostra como a facilidade de acesso foi importante para a expansão do número de empreendimentos. A realização de obras pelo PAC, como vias de acesso internas e o elevador mirante mostram a importância do estado para esse processo doturismo em favelas, através de melhorias nos espaços públicos. Cabe ressaltar que ao fazer um elevador com um mirante ao alto fica clara a intenção turística da obra, ao lado da importância para a acessibilidade.

No caso do Cantagalo-Pavão-Pavãozinho o grande número de albergues encontrados (Tabela 02) se deve sobretudo à localização do conjunto de favelas, entre Ipanema e Copacabana, bairros turísticos famosos, perto da praia, e com grande rede hoteleira. No entanto atualmente o número de albergues é reduzido, como mostra a tabela 03. Se por um lado as politicas públicas ajudaram a aumentar o turismo nessas favelas estudadas, o fim de políticas públicas, como o fim das UPPs e o fechamento do Elevado-mirante no final de 2018, no caso do Cantagalo-Pavão-Pavãozinho, contribuíram para a evidente diminuição dessas atividades. 


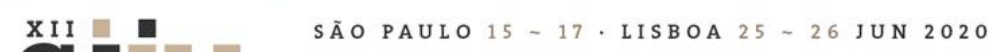 \\ Seminário Internacional de \\ Seminario Internacional de Investigação em Urbanismo

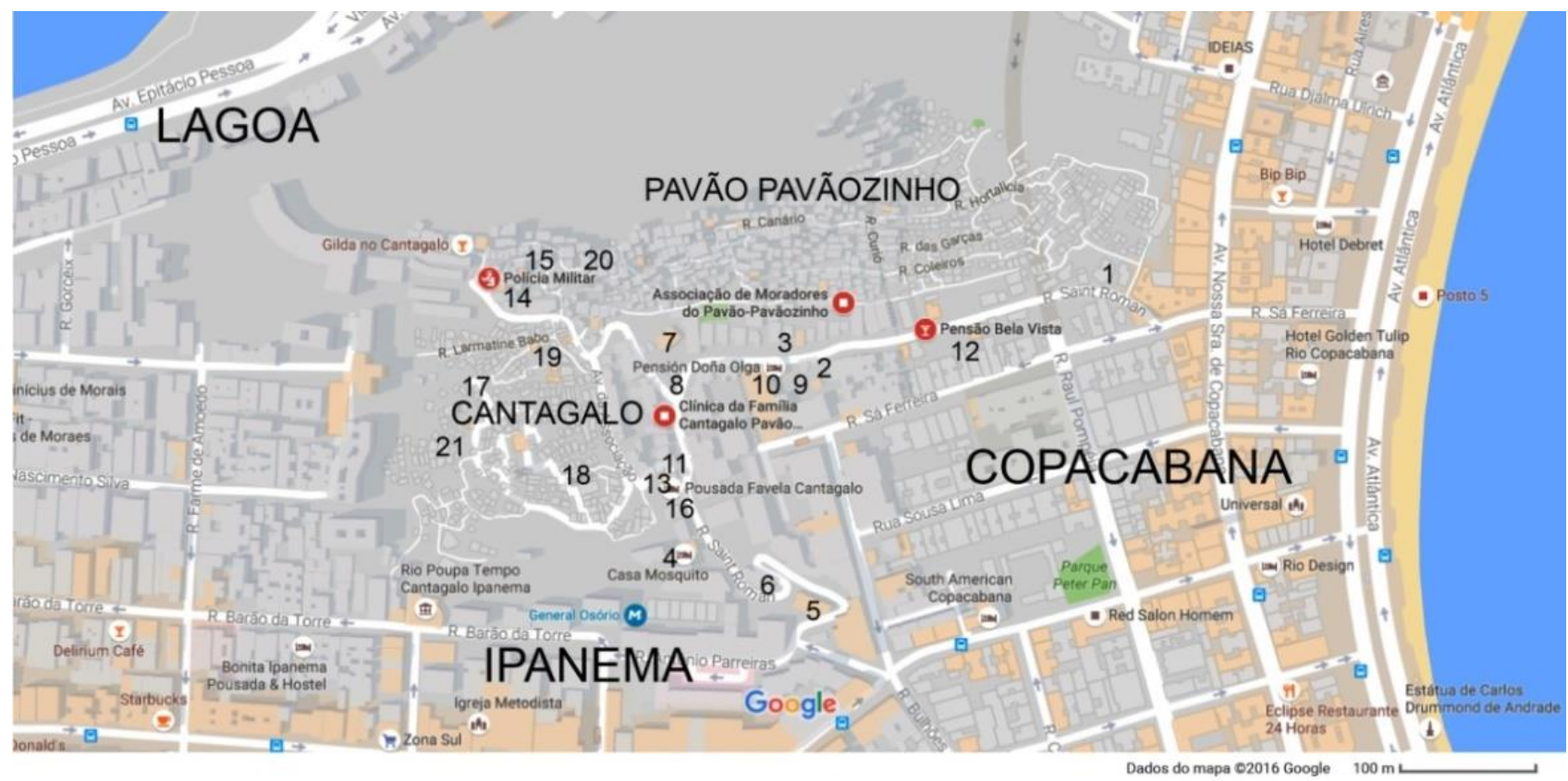

Figura 04: Mapa do conjunto de favelas Cantagalo Pavão Pavãozinho, com localização dos albergues. Fonte: Desenho do autor sobre Google Maps, 2017.

A tabela 21 juntamente com o mapa da figura 04 mostram como a localização se deu durante o periodo estudado, em que a hospedagem nas favelas passou a ser uma possibilidade grande tanto para seus moradores, com empreendimentos de moradores locais, como co ma entrada de empreendedores externos, com aumento do valor dos imóveis, e em alguns casos trazendo um processo de gentrificação, com a chegada de novos moradores.

Por outro lado o uso de antigas residências na principal rua de acesso, a Rua Saint Roman, possibilitou melhorias na relação com os bairros vizinhos, especialmente Copacabana.

\begin{tabular}{|l|l|l|l|}
\hline & nome & endereço & o quartos \\
\hline 1 & Pura Vida Hostel & Rua Saint Roman 20 & 6 \\
\hline 2 & Blue Ocean Hostel /Hostel Rio Pousada & Rua Saint Roman 119 & \\
\hline 3 & Casa do Estudante & Rua Saint Roman 167 & 4 \\
\hline 4 & Casa Mosquito & Rua Saint Roman 222 & 5 \\
\hline 5 & Colinas Residência & Rua Saint Roman 338 & \\
\hline 6 & Abbey of Design & Rua Saint Roman 301 & \\
\hline 7 & Casa del Angel (Pousada del Angel) & Rua Saint Roman 154 & 11 \\
\hline 8 & Pousada Dona Julia Copacabana & Rua Saint Roman 154 & 30 \\
\hline 9 & Copa Green Hostel & Rua Saint Roman 127 & 9 \\
\hline 10 & Pension D. Olga & Rua Saint Roman 135 & \\
\hline
\end{tabular}




\section{SÃO PAULO15 17 LISBOA $25 \sim 26$ JUN 2020 \\ Seminário Internacional de Investigação em Urbanismo \\ Seminario Internacional de Investigación en Urbanismo}

\begin{tabular}{|c|l|l|l|}
\hline 11 & Club House Rio & Rua Saint Roman 184 & 3 \\
\hline 12 & Caixa Preta & Rua Saint Roman 43 & 10 \\
\hline 13 & Pousada Favela Cantagalo & Rua Saint Roman 200 & 2 \\
\hline 14 & Chateau Hostel Rio & Estrada do Cantagalo & 9 \\
\hline 15 & Tiki Hostel Cantagalo & Estrada do Cantagalo & \\
\hline 16 & Homestay Girassol & Rua Saint Roman 200 & \\
\hline 17 & Casa de Cris & & 6 \\
\hline 18 & Vizu do Galo & & 3 \\
\hline 19 & Home Hostel Cantagalo & Rua Pedro Ernesto 29 & \\
\hline 20 & Hostel do Rocha & Estrada do Cantagalo 160 & \\
\hline 21 & Simone Home Hostel & Pag do Cantagalo & \\
\hline
\end{tabular}

Tabela 02: Lista de albergues na Favela do Cantagalo Pavão Pavãozinho, Fonte: Realizado pelo autor, 2017.

\section{Crise de 2016 e o momento pós grandes eventos}

Os Jogos Olímpicos no Rio de Janeiro já aconteceram em um momento de crise financeira do estado, e grande preocupações com a segurança pública. O fim da política de segurança já era percebido em diversas favelas, com o aumento da sensação de insegurança, e a volta do crime organizado de forma visível. O turismo nas favelas sentiu o efeito da crise das UPP em 2016/2017, e muitas das favelas turísticas, até então pacificada, voltaram a apresentar conflitos armado. Os reflexos dessa situação com a diminuição da movimentação de turistas nas favelas ficam claramente demonstrados através da diminuição do número de albergues em duas favelas pesquisadas, Santa Marta e Cantagalo-Pavão-Pavãozinho (Tabela 03).

\begin{tabular}{|c|c|c|c|c|c|c|c|c|c|c|}
\hline Favelas & \multicolumn{10}{|c|}{ Número de albergues } \\
\hline & 2010 & 2011 & 2012 & 2013 & 2014 & 2015 & 2016 & 2017 & 2018 & 2019 \\
\hline $\begin{array}{c}\text { Santa } \\
\text { Marta }\end{array}$ & - & - & - & 1 & 1 & 3 & 3 & 3 & 2 & 1 \\
\hline $\begin{array}{c}\text { Cantagalo } \\
\text { Pavão } \\
\text { Pavãozinho }\end{array}$ & 1 & 6 & 7 & 12 & 14 & 17 & 21 & 18 & 15 & 7 \\
\hline
\end{tabular}

Tabela 03: Tabela com dados de 2010 a 2019. Fonte: Pesquisa do autor.

A série histórica de levantamentos desses empreendimentos mostra como a abertura e fechamento de albergues acompanhou o momento vivenciado pela cidade, e ainda mais pelas favelas. Se em 2010 a favela Santa Marta ainda não apresentava nenhum albergue e o Cantagalo-Pavão-Pavãozinho somente um, em 2016 os números são claros ao mostrar maior quantidade de albergues especialmente no complexo do Cantagalo-Pavão-Pavãozinho. Mesmo com a crise, o turismo em favelas permanece como uma atividade possível. A atuação de ONG's como o Museu de Favela (MUF) no Cantagalo-Pavão-Pavãozinho, com 


\section{SÃOPAULO15 $17 \cdot$ LISBOA $25 \sim 26$ JUN 2020}

atuação principalmente em guiamentos, mostra que mesmo com a diminuição dos locais de hospedagem, as visitas permanecem.

\section{Considerações Finais}

O turismo em favelas viveu momentos de grande crescimento nesses anos em que a cidade viveu a expectativa e depois os próprios eventos esportivos, como a Copa do Mundo de 2014 e os Jogos Olímpicos de 2016. Grandes obras alcançaram lugares excluídos, como as favelas, como os casos citados de equipamentos de mobilidade urbana como o elevador mirante no Cantagalo-Pavão-Pavãozinho e o plano inclinado no Santa Marta. Além disso a implantação de uma política de segurança, as UPP's, trouxe momentaneamente alguma tranquilidade para essas comunidades.

Essa conjunção de fatores favoreceu o turismo em favelas, com alguns projetos públicos como o Rio Top Tour, prosseguindo dinâmicas participativas do Ministério do Turismo naquele momento, com iniciativas de favorecimento de iniciativas ligadas ao Turismo de Base Comunitária (TBC). Assim o crescimento da visitação, do trabalho de guias locais e ONG's, ao lado do surgimento de albergues em áreas dentro e no entorno das favelas aqui pesquisadas possibilitou a expectativa de geração de renda e novas possibilidades para populações ali residentes.

A crise de 2016, e o fim das UPP's em 2018 desmontou em grande parte o que vinha sendo construído. O aumento da violência, e ainda mais da sensação de insegurança vem levado ao fechamento de grande parte dos albergues. A precarização do funcionamento dos equipamentos de mobilidade urbana nessas duas favelas, com o fechamento do elevador mirante do Cantagalo-Pavão-Pavãozinho no final de 2018 e o funcionamento precário do plano inclinado na Santa Marta tem prejudicado não somente os moradores, mas também a visitação ali praticada.

Mesmo assim moradores locais e ONG's, como o MUF, ainda realizam esse trabalho, buscando motivar os moradores e trazer visitantes, não somente em busca de geração de renda mas como resistência, mostrando os problemas e as potencialidades das favelas, a cultura e que não se trata somente de lugares de exclusão, mas de potência.

\section{Bibliografia:}

BARRETTO, H. (2014). Patrimônio cultural como indutor da renovação do centro do Rio. In SHLUGER, E., DANOSKI, M. (org.) Cidades em transformação: Rio de Janeiro, Buenos Aires, Cidade do Cabo, Nova York, Londres, Havana (54-61) Rio de Janeiro: Edições de Janeiro.

BURGOS, M. B., PEREIRA, L. F. A., CAVALCANTI, M., B., M. \& AMOROSO, M. (2011) O efeito UPP na percepção dos moradores das favelas (49-98). Desigualdade \& Diversidade.Revista de Ciências Sociais da PUC-Rio.

CARVALHO, F. C. (2016). O turismo de base comunitária como prática de empoderamento e o caso da favela Santa Marta. Anais do IV Encontro da Associação Nacional de pesquisa e Pós-graduação em Arquitetura e Urbanismo ENANPARQ, Porto Alegre: ENANPARQ.

COMELLI, T., ANGUELOVSKI, I. \& CHU, E. (2018). Socio-spatial legibility, discipline, and gentrification through favela upgrading in Rio de Janeiro. v.22(5-6). (633-656). City, Taylor \& Francis Online. 


\section{SÃOPAULO15 $17 \cdot$ LISBOA $25 \sim 26$ JUN 2020}

FAGERLANDE, S. M. R. (2017). Novas posibilidades económicas, sociais e culturais em áreas informais das cidades: o desenvolvimento do turismo em favelas cariocas entre 2008 e 2016. vol 4 (175-185). Anais do IV Seminário Internacional da Academia de Escolas de Arquitetura e Urbanismo de Lingua Portuguesa. Belo Horizonte: Academia de Escolas de Arquitetura e Urbanismo de Lingua Portuguesa.

(2016) Turismo no Cantagalo-Pavão-Pavãozinho: albergues e mobilidade na favela. Anais do 1ำ Seminário Nacional de Turismo e Cultura. Rio de Janeiro: Fundação Casa de Rui Barbosa. $<$ http://casaruibarbosa.gov.br/> (consulta: 20/01/2016).

FRANCO, M. (2014). UPP-A redução da favela a três letras: uma análise da política de segurança pública do estado do Rio de Janeiro. Niterói: UFF.

FREIRE-MEDEIROS, B. (2009). Gringo na laje: produção, circulação e consumo da favela turística. Rio de Janeiro: Editorial FGV.

FRENZEL, F., KOENS, K. \& STEINBRINK, M. (ed.) (2012). Slum Tourism: poverty, power and ethics. Abingdon, Inglaterra: Routledge.

PERLMAN, J. E.(2016). The formalization of informal real estate transactions in Rio's favelas (58-82). In BIRCH, E. L., CHATTARAJ, S. \& WACHTER, S. M. (ed.). Slums: how informal real estate market work. Philadelphia, EUA: University of Pennsaylvania Press.

PINTO, R. C. Silva, SILVA, C. E. G. \& LOUREIRO, K. A. S. (org) (2012). Circuito das Casas-Tela: Caminhos de vida no Museu de Favela. 1.ed. Rio de Janeiro: Museu de Favela.

RODRIGUES, M. (2014). Tudo junto e misturado: o almanaque da favela: turismo na Santa Marta. 1.ed. Rio de Janeiro: Mar de Idéias.

SILVA, K; T. P., RAMIRO, R. C. \& TEIXEIRA, B. S. (2009) Fomento ao turismo de base comunitária: a experiência do Ministério do Turismo (359-494). In BARTHOLO, R., SANSOLO, D. G. \& BURSZTYN, I. (Orgs.). Turismo de Base Comunitária: diversidade de olhares e experiências brasileiras. Rio de Janeiro: Letra e Imagem. <http://www.ivt-ri.net/ivt/bibli/Livro\%20TBC.pdf>. (consulta: 30/06/2009).

STEINBRINK, M., FRENZEL, F. \& KOENS, K. (2012). Deveopment and globalization of a new trend in tourism. In FRENZEL, F., KOENS, K. \& STEINBRINK, M. (ed.). Slum Tourism: poverty, power and ethics. Abingdon, Inglaterra: Routledge.

URRY, J. (2001). O olhar do turista: lazer e viagens nas sociedades contemporãneas. São Paulo: Editora Studio Nobel.

WILHEIM, J. (2014) Cidade, patrimônio e legado (45-53). In SHLUGER, E., DANOSKI, M. (org.) Cidades em transformação: Rio de Janeiro, Buenos Aires, Cidade do Cabo, Nova York, Londres, Havana. Rio de Janeiro: Edições de Janeiro, 2014. 